University of Nebraska - Lincoln

DigitalCommons@University of Nebraska - Lincoln

Faculty Publications: Department of

Entomology

Entomology, Department of

2001

Decapitation Impacting Effect of Topically Applied Chlorpyrifos on Acetylcholinesterase and General Esterases in Susceptible and Resistant German Cockroaches (Dictyoptera: Blattellidae)

No-Joong Park

University of Nebraska-Lincoln

Shripat T. Kamble

Universitiy of Nebraska--Lincoln, skamble1@unl.edu

Follow this and additional works at: https://digitalcommons.unl.edu/entomologyfacpub

Part of the Entomology Commons

Park, No-Joong and Kamble, Shripat T., "Decapitation Impacting Effect of Topically Applied Chlorpyrifos on Acetylcholinesterase and General Esterases in Susceptible and Resistant German Cockroaches (Dictyoptera: Blattellidae)" (2001). Faculty Publications: Department of Entomology. 313.

https://digitalcommons.unl.edu/entomologyfacpub/313

This Article is brought to you for free and open access by the Entomology, Department of at DigitalCommons@University of Nebraska - Lincoln. It has been accepted for inclusion in Faculty Publications: Department of Entomology by an authorized administrator of DigitalCommons@University of Nebraska - Lincoln. 


\title{
Decapitation Impacting Effect of Topically Applied Chlorpyrifos on Acetylcholinesterase and General Esterases in Susceptible and Resistant German Cockroaches (Dictyoptera: Blattellidae)
}

\author{
NO-JOONG PARK AND SHRIPAT T. KAMBLE ${ }^{1}$ \\ Department of Entomology, University of Nebraska, Lincoln, NE 68583-0816
}

\begin{abstract}
J. Econ. Entomol. 94(2): 499-505 (2001)
ABSTRACT The effect of topically applied chlorpyrifos on acetylcholinesterase and other esterases in heads and decapitated bodies of CSMA and Crawford German cockroaches was examined with spectrophotometric enzyme assay and native polyacrylamide gel electrophoresis. The toxicity of chlorpyrifos was greatly reduced in decapitated CSMA male cockroaches with $\mathrm{LD}_{50}$ value 17.1-fold higher than that of normal CSMA cockroaches. Acetylcholinesterase activity from heads was significantly higher in the Crawford compared with the CSMA strain and did not change until $24 \mathrm{~h}$ after chlorpyrifos in vivo treatment in both strains. The $p$-nitrophenyl butyrate (NPB) esterase activities from both heads and decapitated bodies of the resistant Crawford strain were significantly greater than the susceptible CSMA strain. The $p$-NPB esterase activity was significantly inhibited by chlorpyrifos in vivo treatment, and total $p$-NPB esterase activity was significantly reduced in decapitated bodies compared with heads of both strains. Native polyacrylamide gel electrophoresis (PAGE) analysis of extracts solubilized with Triton X-100 from heads and decapitated bodies revealed five major esterase bands and an acetylcholinesterase (AChE) band with a high capability of hydrolyzing $\alpha$-naphthyl butyrate and acetylthiocholine, respectively. In the heads of susceptible CSMA male cockroaches, the activity of mobile isozymes $d 1$ and $d 2$ was completely inhibited at $24 \mathrm{~h}$ after chlorpyrifos application, and isozyme $e$ was partially inhibited. In contrast, isozymes $c 1$ and $c 2$ from the decapitated bodies of CSMA cockroaches were mostly affected at $24 \mathrm{~h}$ after the topical application of chlorpyrifos. The activities of acetylcholinesterase and esterase isozymes $a$ and $b$ from the decapitated body remained uninhibited in both strains. Inhibition of isozymes $d 1$ and $d 2$ seems to be more important in chlorpyrifos intoxication than acetylcholinesterase.
\end{abstract}

KEY WORDS Blattella germanica, resistance, chlorpyrifos, AChE, esterase

ESTERASES ARE CLASSIFIED as hydrolases, a large and diverse group of enzymes that catalyze the hydrolysis of a wide range of aliphatic and aromatic esters, choline esters, and organophorous compounds (Dauterman 1985). The classification of esterases based on the phosphorylation by organophosphate compounds (Aldridge 1953) was developed with the definition of carboxylesterase that catalyzes the hydrolysis of carboxylesters by a two-step process: acylation by a compound and deacylation by a water molecule ( $\mathrm{Au}-$ gustinsson 1958).

Many studies have revealed that organophosphate (OP) and carbamate insecticides act by inhibiting acetylcholinesterase (AChE, EC 3.1.1.7) in vertebrates and invertebrates (Aldridge and Reiner 1972, Silver 1974, Devonshire 1975, Hama 1983, Corbett et al. 1984, Oppenoorth 1985, Siegfried and Scott 1990). $\mathrm{AChE}$ is an important regulatory enzyme responsible for the termination of synaptic nerve impulse transmission in cholinergic nerve synapses in animals. In insects, AChE is the target site of organophosphate and carbamate insecticides and is responsible for the

\footnotetext{
${ }^{1}$ To whom reprint requests should be addressed.
}

intoxication resulting in the death of insects (Eto 1974, Kuhr and Dorough 1976).

Recently, carboxylesterases have received special attention in resistant insects because of the abundance in the insect body, great affinity to organophosphate and carbamate insecticides, and significant overproduction in resistant insects (Pasteur and Georghiou 1989, Byrne and Devonshire 1991, Abdel-Aal et al. 1992). The sequestration of insecticide molecules by overproduced carboxylesterases has been strongly suggested as one of the major detoxification mechanisms in many resistant insects (Devonshire and Moores 1982, Cuany et al. 1993, Chen and Sun 1994), including German cockroach, Blatella germania (L.) (Prabhakaran and Kamble 1995).

Previously, we reported that brain esterases might play an important role in the insecticide resistance of German cockroach because of the significant difference in qualitative and quantitative properties of carboxylesterase in brain homogenates from susceptible and resistant cockroaches (Park and Kamble 1999). However, we were not able to develop a hypothetical mechanism responsible for the involvement of brain esterases in intoxication or detoxication of insecticides because of the lack of specificity toward model sub- 
strates and nonspecific inhibition of the most AChEbinding insecticides. Inhibition of $\mathrm{AChE}$ and binding of other carboxylesterases by organophosphate or carbamate insecticides have been mostly examined with in vitro enzyme assay system incorporating enzyme with insecticide molecule. Examination of the effect on AChE and esterase activity could be a direct approach to understand the involvement of specific esterases in intoxication or detoxication in the insect body after in vivo treatment with insecticide.

This research was undertaken to determine the effectiveness of topically applied chlorpyrifos on AChE and other esterases in heads and decapitated bodies of German cockroaches. We also assessed differences in inhibition of esterase isozymes between insecticidesusceptible and -resistant German cockroaches.

\section{Materials and Methods}

Chemicals. Technical grade chlorpyrifos (>99\% [AI] ) was purchased from ChemService (West Chester, PA). Acetylthiocholine iodite (ATChI), 5,5'-dithiobis (2-nitrobenzoic acid) (DCNB), $p$-nitrophenyl butyrate $(p$-NPB), and $\alpha$-naphthyl butyrate $(\alpha-\mathrm{NB})$ were purchased from Sigma (St. Louis, MO). All other biochemical and electrophoresis reagents were obtained from Sigma (St. Louis) and Bio-Rad (Hercules, CA).

Insects. Insecticide-susceptible (CSMA) and -resistant (Crawford) German cockroaches were used in this experiment. Characteristics of CSMA and Crawford strains used in this study have been reported previously (Park and Kamble 1998, 1999). German cockroaches were reared on Purina dog chow (Ralston Purina, St. Louis, MO) and water, and maintained in Plexiglas containers ( 30.3 by $30.3 \mathrm{~cm}$ by $30.3 \mathrm{~cm}$ ). Cockroach colonies were maintained at $25 \pm 2{ }^{\circ} \mathrm{C}, 60 \pm$ $10 \% \mathrm{RH}$, and a photoperiod of 12:12 (L:D) h.

Bioassay Procedures. Bioassays were conducted with untreated (control) and decapitated males of CSMA and Crawford strains of German cockroach. The decapitated males were able to survive for $>1 \mathrm{wk}$ in a humid chamber at $95 \pm 5 \% \mathrm{RH}$ without any treatment after the removal of heads from bodies with two fine tweezers. Ten adult cockroach males from each group were anesthetized with carbon dioxide, and $0.5 \mu \mathrm{l}$ of acetone with chlorpyrifos was topically applied on the first abdominal sternite. Five to six concentrations of chlorpyrifos were tested per group with three replications. Cockroaches were confined in petri dishes and held at same environmental conditions of colony maintenance. Mortality (no response to probing) was recorded $24 \mathrm{~h}$ after treatment, and analyzed by probit analysis (Raymond 1985).

Enzyme Preparation. Males of CSMA and Crawford German cockroaches were topically treated with 1.25 $\mu \mathrm{g}$ of chlorpyrifos per insect. All cockroach bodies were washed 10 times with $5 \mathrm{ml}$ of acetone at each time to remove residual chlorpyrifos on the body surface before decapitation. Twenty insects were decapitated at 1,8 , and $24 \mathrm{~h}$ after chlorpyrifos treatment with three replications, and acetone-only-treated insects also were decapitated as control. The heads and decapitated bodies were separately homogenized in a glass Potter-Elvehjem homogenizer with $1.5 \mathrm{ml}$ and 5 $\mathrm{ml}$ of of ice-cold $\left(6 \pm 1^{\circ} \mathrm{C}\right) 0.05 \mathrm{M}$ Tris-HCl buffer $(\mathrm{pH}$ 7.8) containing $5 \%$ glycerol, $0.1 \mathrm{M} \mathrm{NaCl}, 0.5 \%$ Triton $\mathrm{X}-100$, and $2.5 \mathrm{mM}$ dithiothreitol. The homogenate was centrifuged for $20 \mathrm{~min}$ at $4^{\circ} \mathrm{C}$ at $15,000 \times g$. The supernatant was filtered through a $1-\mu \mathrm{m}$ glass wool membrane syringe prefilter (Fisher, Pittsburgh, PA) and used as the enzyme source for AChE and $p$-NPB esterase activity assays and native polyacrylamide gel electrophoresis (PAGE). The protein concentration in the supernatant was determined by the protein-dye binding method (Bradford 1976).

Measurement of AChE and Esterase. AChE activity was determined spectrophotometrically at $38^{\circ} \mathrm{C}$ by the method of Ellman et al. (1961) with some modification. The 1.25-ml reaction mixture consisted of $0.05 \mathrm{M}$ Tris-HCl (pH 7.8), 1 mM ATCh, 1 mM DTNB, and 50 $\mu$ l of diluted enzyme solution. Test tubes containing reaction mixture were allowed to equilibrate at the desired temperature for $3 \mathrm{~min}$ in a dry bath incubator (Fischer Scientific, Pittsburgh, PA) before adding the buffer $\left(6 \pm 1^{\circ} \mathrm{C}\right)$. The reaction was initiated with the addition of $100 \mu \mathrm{l}$ of $50 \mathrm{mM}$ ATCh solution, and the solution was transferred to a cuvette in the spectrophotometer after incubation for $10 \mathrm{~min}$. AChE activity was recorded at $412 \mathrm{~nm}$ with a Milton Roy Spectronics 601 spectrophotometer (Rochester, NY). Specific activities were calculated by converting absorbances to molar values with the thionitrobenzoic acid extinction coefficient of $14,150 \mathrm{M}^{-1} \mathrm{~cm}^{-1}$ (Riddles et al. 1979) at $412 \mathrm{~nm}$ and expressed as nanomoles of substrate hydrolyzed per minute per milligram protein. Activity was compared with controls that contained the same reagents and $10 \mu \mathrm{M}$ eserine to correct for hydrolysis of ATCh by nonspecific esterases. Mean specific activity at $10 \mathrm{~min}$ was calculated from two different preparations with three replications.

Esterase assay was performed with a PC-controlled microplate reader (Benchmark, Bio-Rad) by measuring the production of $p$-nitrophenol at $405 \mathrm{~nm}$ from $p$-NPB. The final volume of reaction mixture in the single well of a 96-well microplate was $200 \mu \mathrm{l}$. The mixture was prepared with $50 \mu$ l of diluted enzyme solution, $50 \mu \mathrm{l}$ of $6.25 \mathrm{mM}$ substrate in distilled water, and $100 \mu \mathrm{l}$ of $0.05 \mathrm{M}$ Tris-HCl buffer ( $\mathrm{pH} 7.8$ ). The reaction was initiated by adding $50 \mu \mathrm{l}$ of substrate and incubated at $38^{\circ} \mathrm{C}$. Absorbance was recorded at $5 \mathrm{~min}$ with an enzyme blank for the correction of spontaneous hydrolysis of $p$-NPB, and converted to the amount of product with a standard curve prepared with $p$-nitrophenol, then expressed as micromoles of substrate hydrolyzed per minute per milligram protein. Mean specific activity at $5 \mathrm{~min}$ from each treatment was calculated from two different preparations with five replications.

Differences in mean specific activity of AChE and $p$-NPB esterase were analyzed with GLM procedure followed by Fisher least significant difference (LSD) test (LSD, $\alpha=0.05$ ) (SAS Institute 1996). 


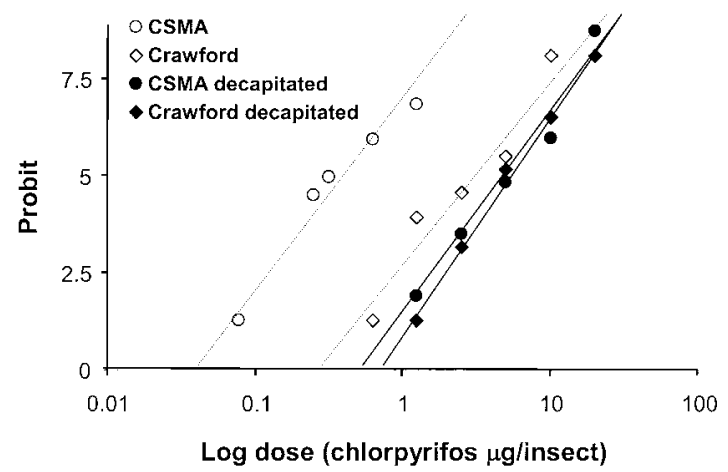

Fig. 1. Dose-probit regression of the normal and decapitated German cockroach males of susceptible CSMA and resistant Crawford strains at $24 \mathrm{~h}$ after topical application of chlorpyrifos. Broken lines with open symbols are resulted from the bioassays with normal cockroach males, whereas solid lines with closed symbols from that with decapitated insects.

Native Electrophoresis. Native polyacrylamide gel electrophoresis was performed in a vertical electrophoresis unit (Protean II mini electrophoresis cell; Bio-Rad) by using a $7.5 \%$ separating and $2.5 \%$ stacking gel $(0.75 \mathrm{~mm}$ thick $)$ with a discontinuous Tris-glycine buffer system. Ten micrograms of protein from head and decapitated body samples of CSMA and Crawford cockroaches of each treatment was loaded in each lane.

AChE activity was stained according to the method of Lewis and Shute (1966). All staining reagents were prepared with $0.05 \mathrm{M}$ Tris-HCl buffer ( $\mathrm{pH} 7.8$ ) and incubation was performed at $60 \mathrm{rpm}$ in a platform shaker (Innova 2100; New Brunswick Scientific, Edison, $\mathrm{NJ}$ ) at room temperature. The gel was preincubated with $70 \mathrm{ml}$ of $10 \mathrm{mM}$ acetylthiocholine for $5 \mathrm{~min}$ and $10 \mathrm{ml}$ of $0.1 \mathrm{M}$ copper sulfate was added drop-wise. Then, $10 \mathrm{ml}$ of $0.2 \mathrm{M}$ glycine and finally $10 \mathrm{ml}$ of potassium ferricyanide were added. The incubation was completed when the background of the gel turned a yellowish brown. After incubation, the gel was washed for $1 \mathrm{~h}$ in three changes of distilled water and prepared for a dry gel film. Detailed procedures for sample buffer composition, PAGE condition, and staining of the esterase activity with $\alpha$-naphthyl butyrate were previously reported (Park and Kamble 1998, 1999).

\section{Results}

Bioassay. The dose-mortality (probit) response of chlorpyrifos on untreated (control) normal and decapitated male cockroaches of susceptible CSMA and resistant Crawford strains is presented in Fig. 1. The $\mathrm{LD}_{50}$ value of chlorpyrifos from the Crawford strain $(3.12 \mu \mathrm{g} /$ insect with $95 \%$ CI of $2.23-4.35)$ was 9.45 fold greater than that from CSMA strain $(0.33 \mu \mathrm{g} /$ insect $95 \%$ CI of $0.30-0.37$ ). A large change of chlorpyrifos toxicity was observed from the bioassay with decapitated CSMA cockroaches. The $\mathrm{LD}_{50}$ values

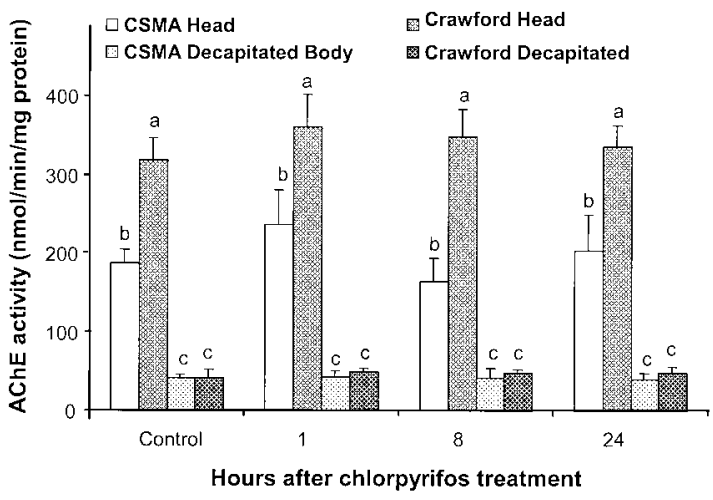

Fig. 2. Specific activity of AChE measured with ACh from the heads and decapitated bodies of susceptible CSMA and resistant Crawford German cockroach males at 1, 8, and $24 \mathrm{~h}$ after topical application of $1.25 \mu \mathrm{g} /$ insect of chlorpyrifos with control of acetone treatment. Different letters above columns indicate statistical significance $(P<0.05)$.

from the assay with decapitated body were not significantly different between strains with $\mathrm{LD}_{50}$ values of $5.61 \mu \mathrm{g} /$ insect (95\% CI of 5.13-6.14) from CSMA strain and $4.94 \mu \mathrm{g} /$ insect (95\% CI of 4.56-5.34) from Crawford strain, respectively. The $\mathrm{LD}_{50}$ values from decapitated CSMA and Crawford cockroaches were 17.1- and 14.9-fold higher than $\mathrm{LD}_{50}$ value from normal CSMA male cockroaches, respectively.

AChE and General Esterase Activity. The data in Fig. 2 depict AChE activity measured with ATCh as substrate from the homogenates of head and decapitated body after topical application of $1.25 \mu \mathrm{g} /$ insect of chlorpyrifos to male cockroaches of CSMA and Crawford strains. AChE activities from heads of the Crawford strain were significantly higher than those of CSMA strain and consistent from control to $24 \mathrm{~h}$ after chlorpyrifos treatment with a range of 1.5- to 2.1-fold, whereas AChE activity from decapitated bodies was not significantly different between strains with a range of $39.5-48.8 \mathrm{nmol} / \mathrm{min} / \mathrm{mg}$ protein. The effect of chlorpyrifos on AChE activity was not significant in both strains and body parts after treatment of chlorpyrifos. AChE activity with a range of 318.0-361.5 $\mathrm{nmol} / \mathrm{min} / \mathrm{mg}$ protein in the head of Crawford cockroaches was significantly higher than that of CSMA with a range of $164.1-236.6 \mathrm{nmol} / \mathrm{min} / \mathrm{mg}$ protein. Levels of AChE activity from both strains were consistently not different from controls to $24 \mathrm{~h}$ after chlorpyrifos treatment. In addition, AChE activity from decapitated bodies was insignificantly different between CSMA and Crawford strains with a range of $39.5-48.7 \mathrm{nmol} / \mathrm{min} / \mathrm{mg}$ protein, and remained at continuous levels after chlorpyrifos treatment.

$p$-NPB esterase activity changed significantly in both control and decapitated treatments of CSMA and Crawford strains. Fig. 3 depicts the $p$-NPB esterase activity measured from heads and decapitated bodies of CSMA and Crawford males. Generally, the $p$-NPB esterase activities from both heads and decapitated bodies of the resistant Crawford strain were signifi- 


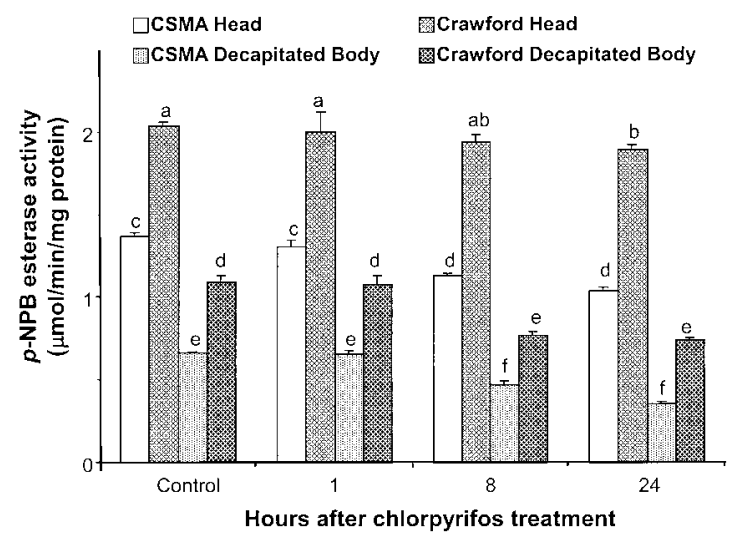

Fig. 3. Specific activity of $p$-NPB esterase from heads and decapitated bodies of susceptible CSMA and resistant Crawford German cockroach males at 1, 8, and $24 \mathrm{~h}$ after topical application of $1.25 \mu \mathrm{g}$ /insect of chlorpyrifos with control of acetone treatment. Different letters above columns indicate statistical significance $(P<0.05)$.

cantly greater than those in the susceptible CSMA strain. Chlorpyrifos treatment was more inhibitory on $p$-NPB esterase activity in the CSMA compared with Crawford cockroaches, and a greater reduction in esterase activity in the decapitated bodies compared with the heads of both strains. $p$-NPB esterase activity from heads and decapitated bodies of the CSMA strain at $24 \mathrm{~h}$ after chlorpyrifos treatment was decreased from 1.37 and $0.66 \mu \mathrm{mol} / \mathrm{min} / \mathrm{mg}$ protein to 1.04 and $0.36 \mu \mathrm{mol} / \mathrm{min} / \mathrm{mg}$ protein (a reduction of 76.2 and $54.1 \%$ compared with control, respectively). For the Crawford strain, $p$-NPB esterase activity from heads and decapitated bodies at $24 \mathrm{~h}$ after chlorpyrifos treatment was reduced to 93.0 and $67.6 \%$ compared with control, respectively.

Native Electrophoresis of AChE and Esterase. AChE analysis of head extracts from CSMA and Crawford male cockroaches with native PAGE revealed two major bands with a high capability of hydrolyzing acetylthiocholine (Fig. 4). Major bands appeared on the top of the gel and the mobility of AChEs was not consistent in the native PAGE gel. No significant decrease of activity was observed between strains, and the treatment of chlorpyrifos did not affect AChE activity from heads. From the decapitated bodies, AChE appeared as broad bands in both strains (Fig. 5).

Esterase isozyme analysis of extracts solubilized with Triton X-100 from heads and decapitated bodies with native PAGE revealed five major bands with a high capability of hydrolyzing $\alpha$-naphthyl butyrate (Figs. 6 and 7). Major bands were previously designated as $a, b, c, d$, and $e$ according to their mobility (Park and Kamble 1998, 1999), and esterase $c$ and $d$ were more extensively separated to $c 1, c 2, d 1$, and day 2 , respectively. In addition, AChE-like esterase was observed in the top of the gels loaded with both head and decapitated body homogenates solubilized with Triton X-100.

In the heads of susceptible CSMA males, the activity of mobile isozymes $d 1$ and $d 2$ was completely inhib-

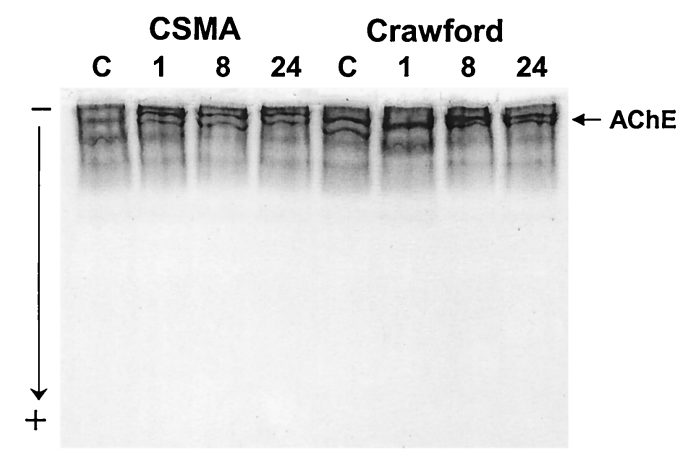

Fig. 4. AChEs from heads of the susceptible CSMA and resistant Crawford German cockroach males at 1, 8, and $24 \mathrm{~h}$ after topical application of $1.25 \mu \mathrm{g} /$ insect of chlorpyrifos, separated by native PAGE and stained with acetylthiocholine as substrate. CSMA, susceptible German cockroach strain; Crawford, resistant German cockroach strain; C, control with acetone; 1,8 , and $24: 1,8$, and $24 \mathrm{~h}$ after topical application of chlorpyrifos, respectively.

ited at $24 \mathrm{~h}$ after chlorpyrifos application, and isozyme $e$ was partially inhibited (Fig. 6 ). Activities of mobile isozymes $d 1$ and $d 2$ also were the highly affected esterases in the heads of Crawford males but they still appeared to have some level of activity. Isozyme $e$ in the heads of Crawford males was slightly affected by chlorpyrifos treatment. Activity of AChE-like esterase and isozyme $a$ and $b$ from heads of both strains appeared to be insensitive to the topically applied chlorpyrifos.

Analysis of esterases from decapitated bodies, revealed that susceptible CSMA male cockroaches were more inhibited by chlorpyrifos than those from the resistant Crawford strain (Fig. 7). Isozymes $c 1$ and $c 2$ from the decapitated bodies of CSMA cockroaches were mostly affected at $24 \mathrm{~h}$ after the topical application of chlorpyrifos, and isozymes $d 1, d 2$, and $e$ were partially inhibited in the same cockroaches. In the

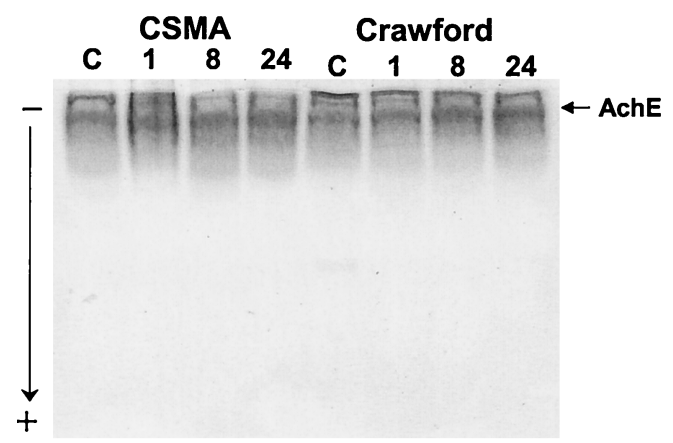

Fig. 5. AChEs from the decapitated bodies of the susceptible CSMA and resistant Crawford German cockroach males at 1,8 , and $24 \mathrm{~h}$ after topical application of $1.25 \mu \mathrm{g} /$ insect of chlorpyrifos, separated by native PAGE and stained with acetylthiocholine as substrate. CSMA, susceptible German cockroach strain; Crawford, resistant German cockroach strain; $\mathrm{C}$, control with acetone; 1,8 , and $24: 1,8$, and $24 \mathrm{~h}$ after topical application of chlorpyrifos, respectively. 


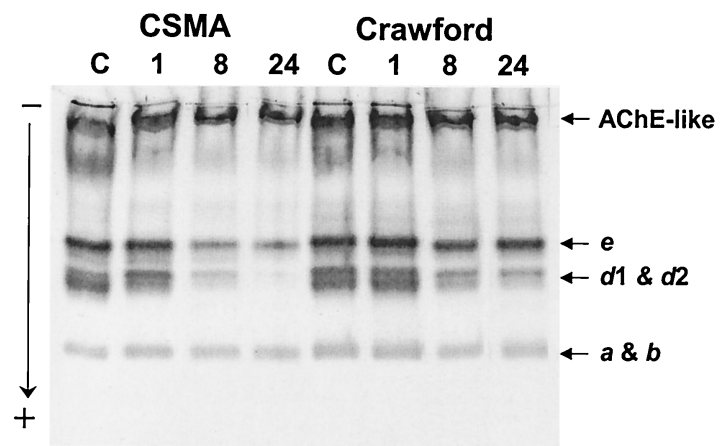

Fig. 6. Esterases from the heads of susceptible CSMA and resistant Crawford German cockroach males at 1, 8, and $24 \mathrm{~h}$ after topical application of $1.25 \mu \mathrm{g} /$ insect of chlorpyrifos, separated by native PAGE and stained with $\alpha$-NPB as substrate. CSMA, susceptible German cockroach strain; Crawford, resistant German cockroach strain; C, control with acetone; 1,8 , and $24: 1,8$, and $24 \mathrm{~h}$ after topical application of chlorpyrifos, respectively.

resistant Crawford strain cockroaches, minor inhibition of isozymes $d 1, d 2$, and $e$ was observed but they maintained significant activity compared with isozymes from the CSMA strain. Activities of putative $\mathrm{AChE}$ and isozyme $a$ and $b$ from decapitated bodies remained unaffected in both strains.

\section{Discussion}

Probit analysis revealed that Crawford male cockroaches showed high levels of resistance to chlorpyrifos with a resistance ratio of 9.4. Interestingly, bioassays with decapitated male cockroach bodies revealed that toxicity of chlorpyrifos was greatly reduced in both strains. The $\mathrm{LD}_{50}$ values of chlorpyrifos were 16.9- and 14.9-fold increased in decapitated bodies of both strains compared with the $\mathrm{LD}_{50}$ values from bioassay with normal CSMA male cockroaches. These findings imply that the insect head is closely related to the intoxication process of topically applied chlorpyrifos resulting in death of the insect because of the greatly increased $\mathrm{LD}_{50}$ values. Thus, the target site for chlorpyrifos appears to be located in the insect head.

Many of the interneurons in the insect brain are involved in integration of sensory inputs and activities, and acetylcholine (ACh) is probably the most widespread excitatory transmitter in insect olfactory neurons, mechanosensory neurons, and interneurons (Chapman 1998). AChE is a serine hydrolase acting on different types of carboxylic esters, and its biological role is the termination of impulse transmissions at cholinergic synapses within the nervous system by rapid hydrolysis of the neurotransmitter $\mathrm{ACh}$ (Schumacher et al. 1986).

Commercially important carbamate and organophosphate insecticides interact with the catalytic center of their target, AChE, as the reaction of enzyme and substrate (Fest and Schmidt 1982, Kuhr and Dorough 1976). There are few studies of insect AChE inhibition with in vivo insecticide treatment (Van

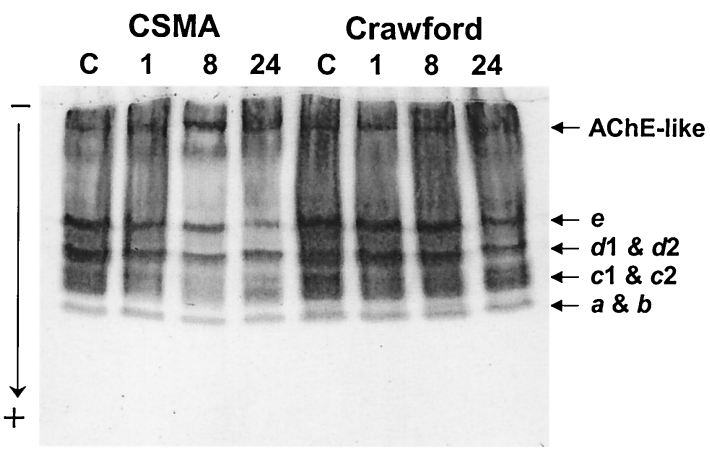

Fig. 7. Esterases from the decapitated bodies of susceptible CSMA and resistant Crawford German cockroach males at 1,8 , and $24 \mathrm{~h}$ after topical application of $1.25 \mu \mathrm{g} /$ insect of chlorpyrifos, separated by native PAGE and stained with $\alpha$-NPB as substrate. CSMA, susceptible German cockroach strain; Crawford, resistant German cockroach strain; C, control with acetone; 1,8 , and $24: 1,8$, and $24 \mathrm{~h}$ after topical application of chlorpyrifos, respectively.

Asperen 1959, Byrne and Devonshire 1991). Most research is performed with crude homogenates or solubilized fractions from insect brains to identify altered AChE (Tripathi et al. 1973, Devonshire 1975, Hemingway and Georghiou 1983, Raymond et al. 1986, Siegfried and Scott 1990, Bonning and Hemingway 1991). But, the toxicity, including AChE inhibition by organophosphate insecticides treated in vivo has been frequently examined with vertebrates and invertebrates of toxicological and environmental importance (Chambers and Levi 1992). Usually, AChE was quickly inhibited (in few hours). However, our data show that AChE from the German cockroach brains and decapitated bodies was not inhibited in $24 \mathrm{~h}$ after topical treatment of chlorpyrifos ( $1.25 \mu \mathrm{g} /$ insect). There are two possibilities to explain this unexpected insensitivity of AChE. One is the low amount of chlorpyrifos in our experiment, and the other is that the AChE might not be primarily inhibited in German cockroach. Inhibition of cholinesterase could be frequently inhibited by the unbound active insecticide molecules freely existing in the tissue out of the target site during sample preparation and homogenization (Kewitz 1957, Van Asperen 1959). The chlorpyrifos amount of $1.25 \mu \mathrm{g} /$ insect might not be enough to inhibit AChE in German cockroaches after the severe washing of cockroach bodies with acetone before homogenization, even though the amount is more than the $\mathrm{LD}_{95}$ against the CSMA susceptible strain. It has been generally accepted that AChE is the target site of organophosphate and carbamate insecticides intoxication in insects and other higher animals. But, we did not observe any significant in vivo inhibition of AChE by chlorpyrifos from the native gel and enzyme assay except complete inhibition of esterases $d 1$ and $d 2$ and partial inhibition of esterase $e$ from brains of susceptible CSMA male cockroaches at $24 \mathrm{~h}$. In control, inhibition of the same esterase isozymes was minor in resistant Crawford male cockroaches (Fig. 6). These results should be examined by in vivo treatment with 
other organophosphate and carbamate insecticides at different dosages and for longer periods.

Addition of $0.5 \%$ Triton X-100 into the homogenization buffer changed the general esterase pattern stained with $\alpha$-naphthyl butyrate in native gel. The esterase isozyme $a$ and $b$ previously appearing in the bottom of the gel with Triton X-100-free buffer (Park and Kamble 1998, 1999) did not clearly separate and the activity was not distinct with Triton X-100 treatment (Figs. 6 and 7). Rather, a new esterase band with increased activity appeared in the top of gel after Triton X-100 treatment (Figs. 6 and 7). The band was not observed at Triton X-100-free homogenization in the previous experiment (Park and Kamble 1998, 1999). The new esterase was identified as putative AChE bands after comparison with the gel pattern stained with ATCh (Figs. 4 and 5). Also, the insensitivity of the putative AChE activity against chlorpyrifos was confirmed in the gel stained with $\alpha$-naphthyl butyrate. Triton X-100 has been used to solubilize membrane-bound or hydrophobic proteins, and frequently used for the preparation of AChE (Ho and Ellman 1969, Devonshire 1975, Siegfried and Scott 1990). In our experiment, we identified AChE bands with other general esterase isozymes from the native gel with $\beta$-naphthyl butyrate as a substrate instead of ATCh.

The inhibition of $p$-NPB esterase significantly appeared at $8-24 \mathrm{~h}$ after chlorpyrifos treatment in the heads and decapitated bodies of both strains of German cockroach (Fig. 3). These reductions of $p$-NPB esterase activity correspond well with the inhibitory patterns of $d 1, d 2$, and $e$ with time course in native gel (Figs. 6 and 7). The inhibition of these esterase isozymes was much more obvious in the CSMA than Crawford samples and in the heads compared with decapitated bodies as mentioned. Esterase isozymes $c 1$ and $c 2$ were also inhibited in the decapitated bodies of CSMA cockroaches. The less inhibitory effect on the Crawford cockroaches might be explained as one major resistance mechanism mediated by esterase. Further research is needed to examine whether the esterase isozymes $c 1$ and $c 2$ are responsible for the sequestration of active insecticide form and the effective sequestration is not enabled in the CSMA cockroaches quantitatively or qualitatively. To understand the involvement and function of these esterases in detoxification of insecticide, the biochemical and pharmacological characterizations in both in vitro and vivo analysis are essential with model insecticides before using the molecular techniques.

Here we report that $\mathrm{AChE}$ is not inhibited in either susceptible CSMA or resistant Crawford strain German cockroaches, whereas some esterase isozymes are completely inhibited only in CSMA head homogenates by in vivo treatment of chlorpyrifos at $1.25 \mu \mathrm{g} /$ insect. In addition, some esterases do not exist in heads and are abundant only in other body parts. These esterases are more sensitive to inhibition in susceptible CSMA male cockroaches. Furthermore, purification and molecular identification of each esterase will be necessary to understand the biological role and resistant involvement of esterases from German cockroaches.

\section{Acknowledgments}

We are grateful to Blair D. Siegfried and Michael E. Scharf (Department of Entomology, University of Nebraska) for their critical review of the manuscript. This article is published as paper No. 13012, Journal Series, NE, Agricultural Division and contribution No. 1074, Department of Entomology, Institute of Agriculture and Natural Resources, University of Nebraska-Lincoln.

\section{References Cited}

Abdel-Aal, Y.A.I., E. P. Lampert, R. M. Roe, and P. J. Semtner. 1992. Diagnostic esterases and insecticide resistance in the tobacco aphid, Myzus nicotianae Blackman (Homoptera: Aphididae). Pestic. Biochem. Physiol. 43: 123133.

Aldridge, W. N. 1953. Serum esterases. 1. Two types of esterase (A and B) hydrolyzing $p$-nitrophenyl acetate, propionate, and butyrate, and a method for their determination. Biochem. J. 53: 110-117.

Aldridge, W. N., and E. Reiner. 1972. Enzyme Inhibitors as Substrates, pp. 1-328. In A. Neuberger and E. L. Tatum [eds.], Frontiers of Biology, vol. 26. North-Holland, Amsterdam.

Augustinsson, K. B. 1958. Eletrophoretic separation and classification of blood plasma esterases. Nature (Lond.) 131: 1786-1789.

Bonning, B. C., and J. Hemingway. 1991. The efficacy of acetylcholinesterase in organophosphorus and carbamate resistance in Culex pipiens $\mathrm{L}$. from Italy. Pestic. Biochem. Physiol. 40: 143-148.

Bradford, M. M. 1976. A rapid and sensitive method for the quantitation of microgram quantities of protein utilizing the principle of protein dye binding. Anal. Biochem. 72: 248-254.

Byrne, F. J., and A. L. Devonshire. 1991. In vivo inhibition of esterase and acetylcholinesterase activities by profenofos treatments in the tobacco whitefly Bemisia tabaci (Genn): Implications for routine biochemical monitoring of these enzymes. Pestic. Biochem. Physiol. 40: 198-204.

Chambers, J. E., and P. E. Levi. 1992. Organophosphates: chemistry, fate, and effects. Academic, San Diego, CA.

Chapman, R. F. 1998. The insects: structure and function, 4th ed. Cambridge University, Oxford.

Chen, W. L., and C. N. Sun. 1994. Purification and characterization of carboxylesterase of rice brown planthopper, Nilaparvata lugens Stal. Insect Biochem. Mol. Biol. 24: 347-355.

Corbett, J. R., K. Wright, and A. C. Baillie. 1984. The Biochemical mode of action of pesticides, 2 nd ed. Academic, London.

Cuany, A., J. Handani, J. Berge, D. Fournier, M. Raymond, G. P. Georghiou, and N. Pasteur. 1993. Action of esterase $\mathrm{B} 1$ on chlorpyrifos in organophosphate resistant Culex mosquitoes. Pestic. Biochem. Physiol. 45: 1-6.

Dauterman, W. C. 1985. Insect metabolism: extramicrosomal, pp. 713-730. In G. A. Kerkut and L. I. Gilbert [eds.], Comprehensive insect physiology, biochemistry, and pharmacology, vol. 12. Pergamon, Oxford.

Devonshire, A. L. 1975. Studies of the acetylcholinesterase from houseflies (Musca domestica L.) resistant and susceptible to organophosphorus insecticides. Biochem. J. 149: 463-469. 
Devonshire, A. L., and G. D. Moores. 1982. A carboxylesterase with broad substrate specificity causes organophosphorus, carbamate and pyrethroid resistance in peach-potato aphids. Pestic. Biochem. Physiol. 18: 235246.

Ellman, G. L., K. D. Courtney, V. Andres, Jr., and B. C. Featherstone. 1961. A new and rapid colorimetric determination of acetylcholinesterase activity. Biochem. Pharmacol. 7: 88-95.

Eto, M. 1974. Organophosphorus pesticides: organic and biological chemistry. CRC, Cleveland, $\mathrm{OH}$.

Fest, C., and K. J. Schmidt. 1982. The chemistry of organophosphorus pesticides, 2nd ed. Springer, Berlin.

Hama, H. 1983. Resistance to insecticides due to reduced sensitivity of acetylcholinesterase, pp. 299-332. In G. P. Georghiou and T. Saito [eds.], Pest resistance to pesticides. Plenum, New York.

Hemingway, J., and G. P. Georghiou. 1983. Studies on the acetylcholinesterase of Anopheles albimanus resistant and susceptible to organophosphate and carbamate insecticides. Pestic. Biochem. Physiol. 19: 167-171.

Ho, I. K., and G. L. Ellman. 1969. Triton solubilized acetylcholinesterase of brain. J. Neurochem. 16: 1505-1513.

Kewitz, H. 1957. A specific antidote against lethal alkyl phosphate intoxication. III. Repair of chemical lesion. Arch. Biochem. Biophys. 66: 263-270.

Kuhr, R. J., and H. W. Dorough. 1976. Carbamate insecticides: Chemistry, biochemistry and toxicology, CRC, Cleveland, $\mathrm{OH}$.

Lewis, P. R., and C.C.D. Shute. 1966. The distribution of cholinesterase in cholinergic neurons demonstrated with the electron microscope. J. Cell. Sci. 1: 381-390.

Oppenoorth, F. J. 1985. Biochemistry and genetics of insecticide resistance, pp. 731-773. In G. A. Kerkut and L. I. Gilbert [eds.], Comprehensive insect physiology, biochemistry, and pharmacology, vol. 12. Pergamon, Elmsford.

Park, N. J., and S. T. Kamble. 1998. Comparison of esterases between life stages and sexes of resistant and susceptible strains of German cockroach (Dictyoptera: Blattellidae). J. Econ. Entomol. 91: 1051-1057.

Park, N. J., and S. T. Kamble. 1999. Distribution and inhibition of esterases in various body tissues of susceptible and resistant German cockroaches (Dictyoptera: Blattellidae). Ann. Entomol. Soc. Am. 92: 556-562.
Pasteur, N., and G. P. Georghiou. 1989. Improved filter paper test for detecting and quantifying increased esterase activity in organophosphate-resistant mosquitoes (Diptera: Culicidae). J. Econ. Entomol. 82: 347-353.

Prabhakaran, S. K., and S. T. Kamble. 1995. Purification and characterization of an esterase isozyme from insecticide resistant and susceptible strains of German cockroach, Blattella germanica (L.). Insect Biochem. Mol. Biol. 25: 519-524.

Raymond, M. 1985. Presentation dun programme danalyse log-probit pour micro-ordinnateur. Cah. ORSTOM Ser. Entomol. Med. Parasitol. 22: 17-121.

Raymond, M., D. Frontier, J. M. Bride, A. Cuany, J. B. Berge, M. Magnin, and N. Pasteur. 1986. Identification of resistance mechanisms in Culex pipiens (Diptera: Culicidae) from southern France: insensitive acetylcholinesterase and detoxifying oxidases. J. Econ. Entomol. 76: 1452-1458.

Riddles, P. W., R. L. Blakeley, and B. Zerner. 1979. Ellman's reagent: 5,5-dithiobis (2-nitrobenzoic acid) - a reexamination. Anal. Biochem. 94: 75-81.

SAS Institute. 1996. SAS systems for windows, version 6.12, SAS Institute, Cary, NC.

Schumacher, M., S. Camp, Y. Maulet, M. Newton, K. MacPhee-Quigley, S. S. Taylor, T. Friedmann, and P. Taylor. 1986. Primary structure of Torpedo californica acetylcholinesterase deduced from its cDNA sequence. Nature (Lond.) 319: 407-409.

Siegfried, B. D., and J. G. Scott. 1990. Properties and inhibition of acetylcholinesterase in resistant and susceptible German cockroaches (Blattella germanica L.). Pestic. Biochem. Physiol. 38: 122-129.

Silver, A. 1974. The biology of cholinesterase, pp. 1-596. In A. Neuberger and E. L. Tatum [eds.], Frontiers of biology, vol. 36. North-Holland, Amsterdam.

Tripathi, R. K., Y. C. Chiu, and R. D. O'Brien. 1973. Reactivity in vitro toward substrate and inhibitors of acetylcholinesterase isozymes from electric eel electroplax and housefly brain. Pestic. Biochem. Physiol. 3: 55-60.

Van Asperen, K. 1959. Toxic action of organophosphorus compounds and esterase inhibition in houseflies. Biochem. Pharmacol. 3: 136-146.

Received for publication 17 May 2000; accepted 29 November 2000 